\title{
Insecticide resistance to organophosphates in Culex pipiens complex from Lebanon
}

\author{
Mike A Osta ${ }^{1 *}$, Zeinab J Rizk' ${ }^{1}$ Pierrick Labbé ${ }^{2}$ Mylène Weill² and Khouzama Knio ${ }^{1}$
}

\begin{abstract}
Background: Analysis of Culex pipiens mosquitoes collected from a single site in Lebanon in 2005, revealed an alarming frequency of ace-1 alleles conferring resistance to organophosphate insecticides. Following this, in 2006 the majority of municipalities switched to pyrethroids after a long history of organophosphate usage in the country; however, since then no studies have assessed the impact of changing insecticide class on the frequency of resistant ace-1 alleles in C. pipiens.
\end{abstract}

Methods: C. pipiens mosquitoes were captured indoors from 25 villages across the country and subjected to established methods for the analysis of gene amplification at the Ester locus and target site mutations in ace-1 gene that confer resistance to organophosphates.

Results: We conducted the first large-scale screen for resistance to organosphosphates in C. pipiens mosquitoes collected from Lebanon. The frequency of carboxylesterase (Ester) and ace-1 alleles conferring resistance to organophosphates were assessed among C. pipiens mosquitoes collected from 25 different villages across the country between December 2008 and December 2009. Established enzymatic assay and PCR-based molecular tests, both diagnostic of the major target site mutations in ace-1 revealed the absence of the F290V mutation among sampled mosquitoes and significant reduction in the frequency of G119S mutation compared to that previously reported for mosquitoes collected from Beirut in 2005. We also identified a new duplicated ace-1 allele, named ace- $1^{D 13}$, exhibiting a resistant phenotype by associating a susceptible and a resistant copy of ace-1 in a mosquito line sampled from Beirut in 2005. Fisher's exact test on ace-1 frequencies in the new sample sites, showed that some populations exhibited a significant excess of heterozygotes, suggesting that the duplicated allele is still present. Starch gel electrophoresis indicated that resistance at the Ester locus was mainly attributed to the Ester ${ }^{2}$ allele, which exhibits a broad geographical distribution.

Conclusions: Our analysis suggests that the frequency of resistant ace-1 alleles in mosquito populations can be downshifted, and in certain cases (F290V mutation) even eliminated, by switching to a different class of insecticides, possibly because of the fitness cost associated with these alleles.

Keywords: Insecticide resistance, Acetylcholine esterase, Culex pipiens

\section{Background}

An important global strategy to contain mosquito-borne diseases is vector control using chemical insecticides. However, the strong dependence on insecticides for mosquito control worldwide and the use of such chemicals in agriculture has led to the physiological resistance of important mosquito vectors in recent years, including

\footnotetext{
* Correspondence: mo07@aub.edu.lb

'Department of Biology, American University of Beirut, Bliss Street, Beirut 11072020, Lebanon

Full list of author information is available at the end of the article
}

Anopheles gambiae [1,2], Aedes aegypti [3-5], and Culex pipiens $[6,7]$. Hence, monitoring insecticide resistance in mosquito populations is crucial in order to ensure the sustainability of vector control programs [8].

Lebanon is a temperate country where two potentially important mosquito vectors of disease are prevalent, $C$. pipiens, which transmits filarial worms, West Nile (WNV) and several encephalitis viruses [9,10], and Aedes albopictus the vector for Chikungunya (CHIKV) [11] and dengue viruses (DENV) [12]. Ae.aegypti, the primary vector of DENV is not present in the country.

\section{Biomed Central}


Despite the prevalence of potential vectors of disease, arboviral diseases are absent from Lebanon with the exception of some cases of WNV infections [13], while WNV has been responsible for numerous and iterative outbreaks in Israel [14], a country at the southern border of Lebanon. In the past, however, both DENV [15] and WNV [16] were highly prevalent in the country and a Dengue epidemic affected thousands of individuals in Beirut between the years 1945 and 1946 [15].

Mosquito control in Lebanon depended heavily on organophosphate (OPs) usage before the year 2006. The most commonly used OPs included, dichlorvos, malathion, diazinon and chlorpyriphos. However, after that date the use of OPs dwindled; dichlorvos, malathion and diazinon were eventually discontinued, while chlorpyriphos has remained in use in a limited number of villages. On the other hand, there has been a significant shift towards the use of pyrethroids in most villages, according to the feedback obtained from several municipalities and major insecticide distributors across the country. The most commonly used pyrethroids are alpha-cypermethrin, deltamethrin and tetramethrin. In Lebanon, insecticides are used almost exclusively to control adult mosquito populations by spraying along the roads in villages and around houses, while no strategies exist to identify and treat larval habitats. Resistance to OPs can be metabolic or due to target site modifications. The former is characterized by the amplification of esterases A and B that sequester these insecticides [17], preventing them from reaching their target, the ace-1 gene-encoded acetylcholinesterase. Target-site modifications are due to three distinct mutations in ace-1, resulting in three substitutions, G119S found in several mosquito species, F290V found only in Culex pipiens, and F331W found only in Culex tritaeniorhynchus, (numbered according to Torpedo californica ace [18]), which independently render the enzyme less sensitive to OP insecticides.

Data from C. pipiens mosquitoes sampled in 2005 from Beirut indicated a high frequency of both G119S and F209V mutations [19]. Here, we conducted a largescale one-year survey, between December 2008 and December 2009, to measure the impact of switching to pyrethroids on the residual OP resistance in C. pipiens mosquito populations. The study involved analysis of gene amplification at the Ester locus and target site mutations in ace-1 gene in mosquitoes captured indoors across the country.

\section{Methods}

\section{Collection sites and mosquito strains}

C. pipiens mosquitoes were collected indoors from 25 villages across Lebanon (Figure 1) in a one year survey between December 2008 and December 2009. C. pipiens reference strains included: SLAB, the susceptible strain

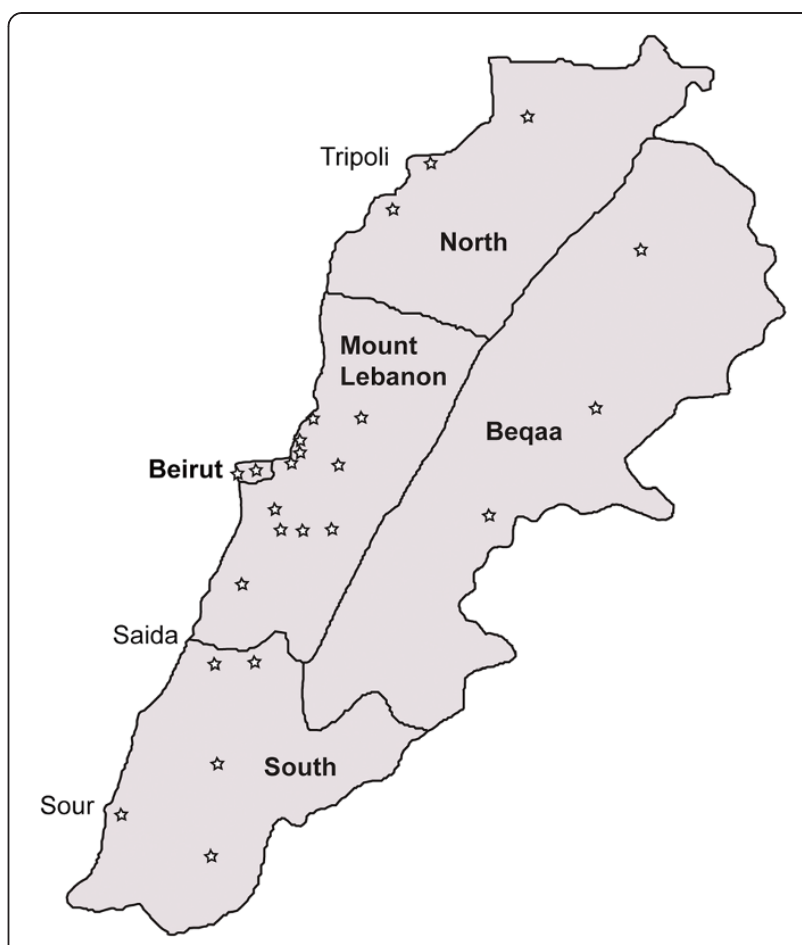

Figure 1 C. pipiens collection sites in Lebanon. In bold are the five geographical regions from where mosquitoes were collected. Stars refer to the collection sites.

lacking overproduced esterases [20]; SA2, a resistant strain homozygous for $E_{s t e r}{ }^{2}$, characterized by overproduction of esterases A2-B2 [21], and the resistant SR strain homozygous for the G119S mutation [22]. Mosquitoes were reared at room temperature. Larval stages were kept in plastic trays $(30 \mathrm{~cm} \times 20 \mathrm{~cm})$ and fed ground fish food (PRODAC), while adult mosquitoes were kept on $10 \%$ sucrose solution.

\section{Starch gel electrophoresis}

The frequency of Ester ${ }^{2}$ (A2-B2) locus among the sampled mosquitoes was determined by Starch gel electrophoresis using TEM 7.4 buffer systems and revealed according to Pasteur et al. [23]. The reference strain SA2 [21] was used as a control for esterase amplification at Ester ${ }^{2}$.

\section{Detection of the G119S and F290V mutations in ace-1}

The G119S mutation was detected using a diagnostic PCR test followed by RFLP, as previously described [24]. Briefly, legs of individual mosquitoes were ground in extraction buffer $(0.1 \mathrm{M}$ Tris-HCl, pH 8.0, 0.01 M EDTA, 1.4 M $\mathrm{NaCl}, 2 \%$ cetyltrimethyl ammonium bromide), DNA was then extracted with chloroform, precipitated in isopropanol, and resuspended in sterile water. A 374 bp amplicon was amplified from exon 3 of ace-1 gene using the primers CpEx3dir, 5'-CGACTCGGACCCACTCGT-3', and CpEx3rev, 5'-GACTTGCGACACGGTACTGCA-3', and the 
following PCR conditions: 30 cycles, $95{ }^{\circ} \mathrm{C}$ for $5 \mathrm{~min}$, $95{ }^{\circ} \mathrm{C}$ for $40 \mathrm{sec}, 60{ }^{\circ} \mathrm{C}$ for $1 \mathrm{~min}$ and $72{ }^{\circ} \mathrm{C}$ for $50 \mathrm{sec}$. Since the G119S mutation in exon 3 creates an AluI restriction site [24], the PCR product was digested with AluI (this generates two fragments of 272 and $102 \mathrm{bp}$ ) and products were analyzed on $1.5 \%$ agarose gel. Detection of the F290V mutation was performed using the PASA diagnostic test as previously described [25] except that the PCR conditions were modified as follows: 30 cycles, $95{ }^{\circ} \mathrm{C}$ for 5 min, $95^{\circ} \mathrm{C}$ for $40 \mathrm{~s}, 61^{\circ} \mathrm{C}$ for $1 \mathrm{~min}$ and $72{ }^{\circ} \mathrm{C}$ for $50 \mathrm{~s}$.

\section{Témoin-dichlorvos-propoxur- (TDP) test}

The TDP test was performed exactly as described by Alout et al. [19] to identify all possible phenotypes at the ace- 1 locus: phenotype [V], mosquitoes containing only the F290V mutated enzyme; [RR], mosquitoes containing only the G119S mutated enzyme, [SS] those containing susceptible enzyme; [VS], [VR], [RS] and [VRS], mosquitoes containing two or three (VRS) enzyme forms.

\section{Detection of ace-1 gene duplications}

The genetic test developed by Labbé et al. [6] was used to detect the presence of duplicated alleles. Briefly, females from field $C$. pipiens populations were crossed with males from the susceptible reference SLAB strain. After blood feeding, females were isolated individually, allowed to produce egg rafts and then phenotyped using the TDP enzymatic test [25]. The progeny of each female appearing as heterozygotes $[\mathrm{R} / \mathrm{S}]$ were reared separately and second instar larvae selected with $1 \mathrm{mg} / \mathrm{l}$ propoxur, a dose that kills all susceptible [S/S] individuals. Only the progenies of females carrying a duplicated allele displayed no mortality following the exposure to this insecticide. Real heterozygous $[\mathrm{R} / \mathrm{S}]$ non-duplicated individuals generate $[\mathrm{S} / \mathrm{S}]$ individuals in their progenies after crossing with susceptible males (for more explanations, see Figure 2 in [6]). DNA was extracted from frozen females, a fragment of the ace-1 gene encompassing intron 2 and exon 3 was PCR-amplified, and the products were cloned (to separate the different copies), as previously described [6]. Sequences were then analyzed using the Mega 5 software (http://www.megasoftware. net/ [26]): Beirut duplicated allele sequences were aligned with known duplicated alleles using ClustalW and a similarity tree was built using Neighbor-Joining with default parameters.

Due to the similarity of duplicated allele sequences with non-duplicated ace-1 alleles, it is not possible to directly detect the presence of the duplicated allele in natural populations $[6,27]$. However, an excess of heterozygote phenotypes at the ace-1 locus have been shown to suggest robustly the presence of a duplicated allele in a population [28,29]. Thus, excess of heterozygotes (as

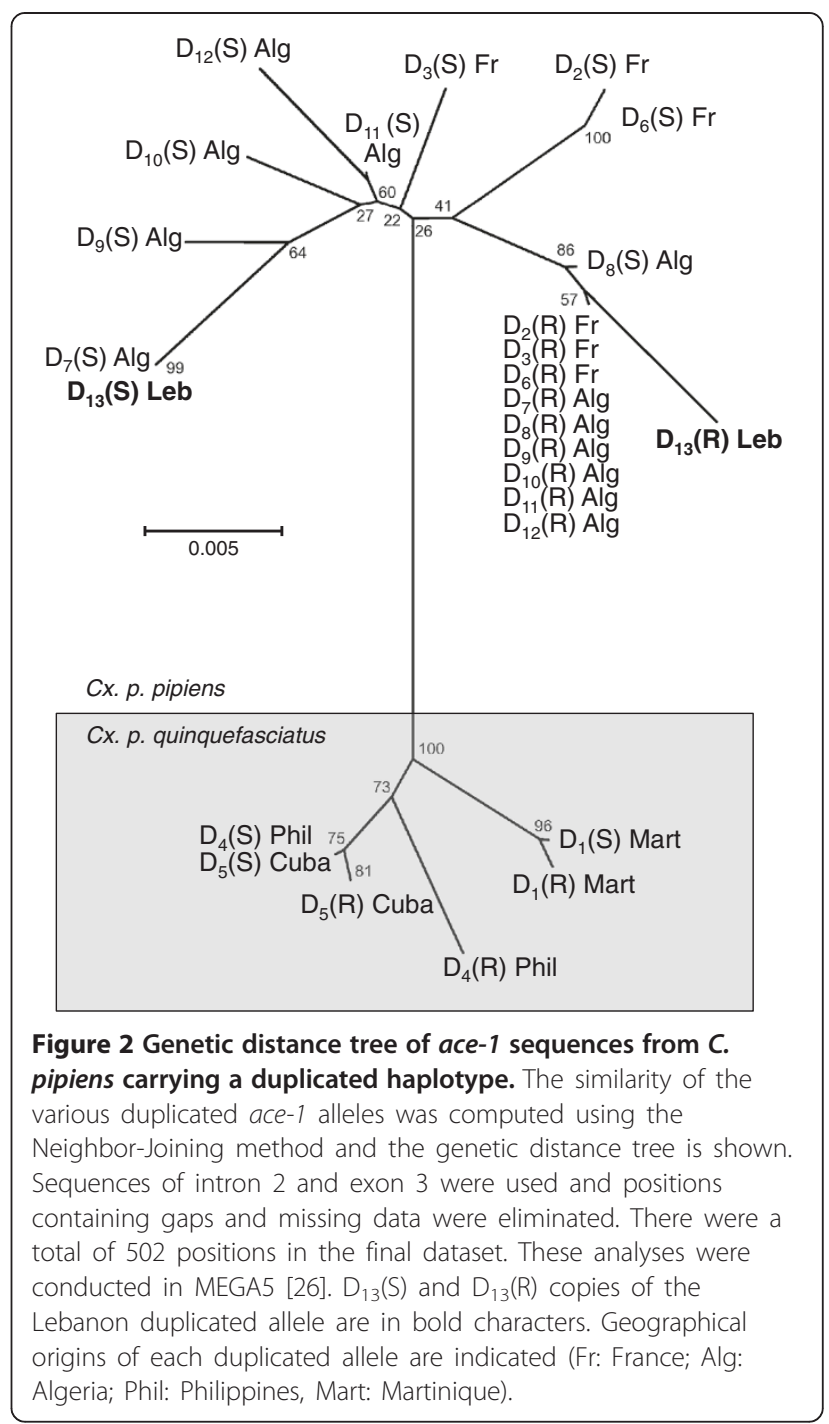

indicated by a negative $F_{\text {is }}$, i.e. a significant departure from the expected frequencies under Hardy-Weinberg assumptions) was tested for each sampled population using the Genepop software (Fisher's exact tests, [30]).

\section{Results and discussion}

\section{Prevalence of Ester ${ }^{2}$ in sampled mosquitoes}

There are many Ester alleles associated with resistance to OPs, the most common type is Ester ${ }^{2}$, which exhibits a worldwide distribution [31,32]. We used starch gel electrophoresis to identify amplifications at the Ester locus. The reference strain SA2 [21] was used as a control for the presence of the Ester ${ }^{2}$ allele, since preliminary data indicated a high frequency of this allele in a sample collected from Beirut in 2005 (M. Weill, unpublished data). The 2008-2009 survey indicated that approximately $40.8 \%$ of sampled mosquitoes carried the Ester $^{2}$ (A2-B2) resistance allele (Table 1), while the rest showed no other resistance allele at that locus. This, 
Table 1 Frequency of Ester $^{2}$ phenotype in the mosquito populations sampled

\begin{tabular}{lcll}
\hline Location & $\mathbf{N}$ & None & {$\left[\right.$ Ester $^{2}$ ] } \\
\hline Beirut & 64 & $0.67(43)$ & $0.33(21)$ \\
Mount Lebanon & 90 & $0.60(54)$ & $0.40(36)$ \\
South Lebanon & 183 & $0.51(93)$ & $0.49(90)$ \\
North Lebanon & 153 & $0.61(94)$ & $0.39(59)$ \\
Beqaa & 134 & $0.63(85)$ & $0.37(49)$ \\
Total number & 624 & 369 & 255 \\
\hline
\end{tabular}

Indicated are the frequencies of the normal (None) and Ester ${ }^{2}$ phenotypes together with the corresponding number of individuals (in brackets) from the different geographical locations. $\mathrm{N}$ is the number of mosquitoes analyzed.

apparently high prevalence, probably reflects the continuous, though limited use of chlorpyriphos in some villages. Moreover, cypermethrin, a pyrethroid used in many municipalities in Lebanon, is known in other organisms to select for resistance due to elevated esterase production [33].

\section{Geographical distribution of AChE1 G119S substitution and evidence for ace-1 duplication}

The analysis of insecticide resistance in a small sample of C. pipiens mosquitoes collected from Beirut in 2005 revealed an alarming frequency of the G119S resistant AChE1 distributed as follows [19]: 41.4\% [RS], 37.9\% [RR], 8.6\% [VS] and 12.1\% [VRS]. None of the mosquitoes sampled exhibited the [SS] phenotype (susceptible enzyme), suggesting that in 2005 there was indeed a strong selective pressure on the ace-1 locus due to the past heavy usage of OPs. Here, we screened a mosquito line, that was selected with OP for several generations from this 2005 Beirut sample, for the presence of a duplicated ace-1 allele as previously reported [6]. The duplicated ace-1 allele (or haplotype) originated from duplication of the $a c e-1$ gene (termed $a c e-1^{D}$ or $\mathrm{D}$ ) which associates a resistant and a susceptible copy (termed $\mathrm{D}(\mathrm{R})$ and $\mathrm{D}(\mathrm{S})$, respectively), resulting in "permanent heterozygotes" [6]. This screen revealed the presence of a new duplicated allele associating the $\mathrm{D}_{7} \mathrm{~S}$ susceptible copy already found in Algeria [34] and a new DR resistant copy (Figure 2), hence exhibiting an overall resistant phenotype. This new allele (as of the complete haplotype) should thereafter be named $a c e-1^{D 13}$, according to previous nomenclature [34] $\left(\right.$ ace- $1^{D 13}$ susceptible and resistant copies are available in GenBank under references JX007790 and JX007791, respectively. All other duplicated alleles can be found in GenBank under references JX007766 to JX007789). Also, considering only the G119S mutation, the ace-1 allele frequencies in the 2005 sample reported above [19] show a significant departure from the Hardy-Weinberg equilibrium (Genepop, [30], Fisher's exact-test for an excess of heterozygotes; $\mathrm{F}_{\text {is }}=-0.34, p$-value $\left.=0.018\right)$. This provides additional support to the presence of at least one ace-1 duplicated allele in the 2005 Beirut sample, as previously reported in other locations $[27,35]$.

In our more recent samples collected between December 2008 and December 2009, we identified only two genotypes associated with the ace-1 locus using PCR analysis; mosquitoes carrying only the susceptible ace-1 allele [SS] and mosquitoes carrying one susceptible and one resistant ace-1 alleles [RS]. The frequency of [SS] ranged from 0.74 to 0.82 across the five geographical regions, while [RS] ranged between 0.17 and 0.25 (Table 2). The TDP assay gave similar results: the frequency of [SS] and [RS] were 0.76 and 0.24 , respectively, in the pool of sampled mosquitoes. Our data suggest that switching to pyrethroids resulted in a dramatic reduction in frequency of resistant mosquitoes, possibly because of the fitness cost associated with this mutation in the absence of a selecting insecticide [36,37]; Indeed, [RR] mosquitoes, supposedly the ones with the highest fitness cost, disappeared. The G119S mutation is known to significantly reduce the enzymatic activity of AChE1 in cholinergic synapses affecting the behavior of mosquitoes, which is probably the cause of this fitness cost [38]. We did not perform genetic crosses to determine whether the $[\mathrm{RS}]$ phenotype represented a heterozygous state or was due to the presence of the duplicated allele, since no mosquito lines were maintained from the 2008-2009 collection sites. However, statistical analyses on the ace-1 frequencies showed that all populations exhibited an excess of heterozygotes, which was significant in the Mount and South Lebanon populations (Table 2), suggesting that the duplicated allele is still present $[27,35]$. This type of duplicated allele is thought to be less costly than the single $R$ allele, although it is

Table 2 Frequency of ace-1 alleles based on diagnostic PCR analysis

\begin{tabular}{llllcccc}
\hline Location & $\mathbf{N}$ & [SS] & [RS] & [RR] & [V] & $\mathbf{F}_{\text {is }}$ & $\boldsymbol{p}$-value \\
\hline Beirut & 76 & $0.763(58)$ & $0.236(18)$ & 0 & 0 & -0.13 & 0.32 \\
$\begin{array}{l}\text { Mount } \\
\text { Lebanon }\end{array}$ & 182 & $0.73(133)$ & $0.27(49)$ & 0 & 0 & -0.15 & $\mathbf{0 . 0 2}$ \\
$\begin{array}{l}\text { South } \\
\text { Lebanon }\end{array}$ & 159 & $0.742(118)$ & $0.258(41)$ & 0 & 0 & -0.14 & $\mathbf{0 . 0 5}$ \\
$\begin{array}{l}\text { North } \\
\text { Lebanon }\end{array}$ & 120 & $0.80(96)$ & $0.20(24)$ & 0 & 0 & -0.11 & 0.28 \\
$\begin{array}{l}\text { Beqaa } \\
\begin{array}{l}\text { Total } \\
\text { number }\end{array}\end{array}$ & 107 & $0.822(88)$ & $0.178(19)$ & 0 & 0 & -0.09 & 0.41 \\
\end{tabular}

Indicated are the frequencies for each genotype together with the corresponding number of individuals in brackets. $\mathrm{N}$ is the number of mosquitoes analyzed. SS, susceptible mosquitoes; RS, mosquitoes heterozygous for G119S; RR, mosquitoes homozygous for G119S; V, mosquitoes containing the $\mathrm{F} 290 \mathrm{~V}$ mutation. The $\mathrm{F}_{\text {is }}$ value indicates whether there is an excess (negative value) or a deficit (positive value) of heterozygotes. The $p$-value (Genepop [30], Fisher's exact test) is also indicated. Significant values are in bold. 
not always the case [6,35]. However, the observed reduction of $[\mathrm{RS}]$ indicates that the duplicated allele is undoubtedly less fit than the susceptible one in the absence of insecticides. We endeavored to collect information on the history of insecticide usage from the municipalities corresponding to the different collection sites; this task was difficult because Lebanon is a free market and there are no unified guidelines for insecticide usage in the country. The information gathered from 31 villages across the country revealed that $5-10 \%$ of municipalities are still using chlorpyrifos (an OP) either alone or in combination with pyrethroids, which probably explains why the G119S mutation is still present at low frequencies in C. pipiens populations.

Interestingly, the F290V substitution that was previously detected at low frequency only in five Mediterranean countries including Lebanon [19], was not detected in the present study using both the PASA (Table 2) and TDP tests, despite the large samples collected across the country. A plausible explanation for the disappearance of the F290V substitution from natural populations is the increased resort to pyrethroids, which do not select for this mutation. Moreover, even in municipalities where chlorpyriphos is still used, the resistance conferred by the F290V mutation to this insecticide is 150fold weaker than that conferred by G119S, according to Alout et al. [25]. Thus, high fitness cost in addition to weak insecticide selection of the F290V AChE1 may explain the loss of this mutation from C. pipiens in Lebanon. The reason why F290V was prevalent at low frequencies in samples collected from Beirut in 2005 may be due to the insecticide dichlorvos which was commonly used at that time together with chlorpyriphos. F290V was shown to confer approximately 10 fold higher resistance to dichlorvos compared to the G119S mutation [25].

\section{Conclusions}

In summary, this study shows that the frequencies of resistant ace-1 alleles carrying the G119S and F290V substitutions were dramatically reduced in C. pipiens mosquitoes collected between 2008 and 2009 when compared to those recorded in 2005. This is probably due to increased dependence on pyrethroid insecticides in recent years that do not select for these mutations. We propose that using a rotation system, whereby the use of different classes of insecticides is alternated on a yearly basis, should maintain resistance ace-1 alleles at a low frequency in C. pipiens mosquitoes. Nevertheless, cross-resistance between pyrethroids and OP through elevated esterases should be considered and evaluated.

\section{Competing interests}

The authors declare that they have no competing interests.

\section{Acknowledgements}

We thank all friends who helped in mosquito collections. We also thank the different municipalities, Boecker International Sal and Debbane Group for providing information regarding insecticide usage in Lebanon. MAO and KK were funded by AUB-URB and Lebanese CNRS, MW was funded by CNRS institutional grants. All sequence data were obtained on the Environmental Genomic Platform of the SFR Montpellier-Environnement-Biodiversité.

\section{Author details}

${ }^{1}$ Department of Biology, American University of Beirut, Bliss Street, Beirut 11072020, Lebanon. ${ }^{2}$ Team Genomics of Adaptation, CNRS UMR 5554 Institut des Science de I'Evolution, Université Montpellier 2, Place E. Bataillon, 34095 Montpellier cedex 05, France.

\section{Authors' contributions}

MAO, KK and MW conceived the study. ZR performed the diagnostic PCR analysis and TDP enzymatic assays. Statistical analysis and ace-1 duplication studies were performed by MW and PL. All authors were involved in data analysis and interpretation. MAO drafted the manuscript. KK, PL and MW critically revised the manuscript. All authors read and approved the final version.

Received: 28 March 2012 Accepted: 3 July 2012

Published: 3 July 2012

\section{References}

1. Koekemoer LL, Spillings BL, Christian RN, Lo TC, Kaiser ML, Norton RA, Oliver SV, Choi KS, Brooke BD, Hunt RH, et al: Multiple insecticide resistance in anopheles gambiae (Diptera: Culicidae) from pointe Noire, Republic of the Congo. Vector Borne Zoonotic Dis 2011, 11:1193-1200.

2. Koffi AA, Alou LP, Adja MA, Kone M, Chandre F, N'Guessan R: Update on resistance status of Anopheles gambiae s.s. to conventional insecticides at a previous WHOPES field site, "Yaokoffikro", 6 years after the political crisis in Cote d'Ivoire. Parasit Vectors 2012, 5:68.

3. Dusfour I, Thalmensy V, Gaborit P, Issaly J, Carinci R, Girod R: Multiple insecticide resistance in Aedes aegypti (Diptera: Culicidae) populations compromises the effectiveness of dengue vector control in French Guiana. Mem Inst Oswaldo Cruz 2011, 106:346-352.

4. Kamgang B, Marcombe S, Chandre F, Nchoutpouen E, Nwane P, Etang J, Corbel V, Paupy C: Insecticide susceptibility of Aedes aegypti and Aedes albopictus in Central Africa. Parasit Vectors 2011, 4:79.

5. Lima EP, Paiva MH, de Araujo AP, da Silva EV, da Silva UM, de Oliveira LN, Santana AE, Barbosa CN, de Paiva Neto CC, Goulart MO, et al: Insecticide resistance in Aedes aegypti populations from Ceara Brazil. Parasit Vectors 2011, 4:5.

6. Labbe P, Berthomieu A, Berticat C, Alout H, Raymond M, Lenormand T, Weill $\mathrm{M}$ : Independent duplications of the acetylcholinesterase gene conferring insecticide resistance in the mosquito Culex pipiens. Mol Biol Evol 2007, 24:1056-1067

7. Liu Y, Zhang H, Qiao C, Lu X, Cui F: Correlation between carboxylesterase alleles and insecticide resistance in Culex pipiens complex from China. Parasit Vectors 2011, 4:236.

8. Ranson H, N'Guessan R, Lines J, Moiroux N, Nkuni Z, Corbel V: Pyrethroid resistance in African anopheline mosquitoes: what are the implications for malaria control? Trends Parasitol 2010, 27:91-98.

9. Farajollahi A, Fonseca DM, Kramer LD, Marm Kilpatrick A: "Bird biting" mosquitoes and human disease: a review of the role of Culex pipiens complex mosquitoes in epidemiology. Infect Genet Evol 2011, 11:1577-1585

10. Kilpatrick AM: Globalization, land use, and the invasion of West Nile virus. Science 2011, 334:323-327.

11. Thiboutot MM, Kannan S, Kawalekar OU, Shedlock DJ, Khan AS, Sarangan G, Srikanth P, Weiner DB, Muthumani K: Chikungunya: a potentially emerging epidemic? PLoS Negl Trop Dis 2010, 4:e623.

12. Lambrechts L, Scott TW, Gubler DJ: Consequences of the expanding global distribution of Aedes albopictus for dengue virus transmission. PLoS Negl Trop Dis 2010, 4:e646.

13. Gallian P, de Micco P, Ghorra P: Seroprevalence of West Nile virus in blood donors at Hotel Dieu de France, Beirut, Lebanon. Transfusion 2010, 50:1156-1158 
14. Weinberger M, Pitlik SD, Gandacu D, Lang R, Nassar F, Ben David D, Rubinstein E, Izthaki A, Mishal J, Kitzes R, et al: West Nile fever outbreak, Israel, 2000: epidemiologic aspects. Emerg Infect Dis 2001, 7:686-691.

15. Hitti J, Khairallah A: A report of recent epidemic of Dengue in Beirut, Lebanon, and some of its complications. J Pales Arab Med Assoc 1945, 1:150.

16. Garabedian GA, Matossian RM, Musalli MN: Serologic evidence of arbovirus infection in Lebanon. J Med Liban 1971, 24:339-350

17. Vaughan A, Hawkes N, Hemingway J: Co-amplification explains linkage disequilibrium of two mosquito esterase genes in insecticide-resistant Culex quinquefasciatus. Biochem J 1997, 325(Pt 2):359-365.

18. Duval N, Bon S, Silman I, Sussman J, Massoulie J: Site-directed mutagenesis of active-site-related residues in Torpedo acetylcholinesterase. Presence of a glutamic acid in the catalytic triad. FEBS Lett 1992, 309:421-423.

19. Alout H, Labbe P, Berthomieu A, Pasteur N, Weill M: Multiple duplications of the rare ace-1 mutation F290V in Culex pipiens natural populations. Insect Biochem Mol Biol 2009, 39:884-891.

20. Georghiou GP, Metcalf RL, Gidden FE: Carbamate-resistance in mosquitos. Selection of Culex pipiens fatigans Wiedemann $(=C$. quinquefasciatus Say) for resistance to Baygon. Bull World Health Organ 1966, 35:691-708.

21. Berticat C, Rousset F, Raymond M, Berthomieu A, Weill M: High Wolbachia density in insecticide-resistant mosquitoes. Proc Biol Sci 2002, 269:1413-1416.

22. Berticat C, Boquien G, Raymond M, Chevillon C: Insecticide resistance genes induce a mating competition cost in Culex pipiens mosquitoes. Genet Res 2002, 79:41-47.

23. Pasteur N, Iseki A, Georghiou GP: Genetic and biochemical studies of the highly active esterases $A^{\prime}$ and $B$ associated with organophosphate resistance in mosquitoes of the Culex pipiens complex. Biochem Genet 1981, 19:909-919.

24. Weill M, Malcolm C, Chandre F, Mogensen K, Berthomieu A, Marquine M, Raymond $\mathrm{M}$ : The unique mutation in ace-1 giving high insecticide resistance is easily detectable in mosquito vectors. Insect Mol Biol 2004, 13:1-7.

25. Alout $H$, Berthomieu A, Hadjivassilis A, Weill M: A new amino-acid substitution in acetylcholinesterase 1 confers insecticide resistance to Culex pipiens mosquitoes from Cyprus. Insect Biochem Mol Biol 2007, 37:41-47.

26. Tamura K, Peterson D, Peterson N, Stecher G, Nei M, Kumar S: MEGA5: molecular evolutionary genetics analysis using maximum likelihood, evolutionary distance, and maximum parsimony methods. Mol Biol Evol 2011, 28:2731-2739

27. Djogbenou L, Labbe P, Chandre F, Pasteur N, Weill M: Ace-1 duplication in Anopheles gambiae: a challenge for malaria control. Malaria J 2009, 8:70

28. Djogbenou L, Noel V, Agnew P: Costs of insensitive acetylcholinesterase insecticide resistance for the malaria vector Anopheles gambiae homozygous for the G119S mutation. Malaria J 2010, 9:12

29. Lenormand T, Guillemaud T, Bourguet D, Raymond M: Appearance and sweep of a gene duplication: adaptive response and potential for new functions in the mosquito Culex pipiens. Evolution 1998, 52:1705-1712.

30. Raymond M, Rousset F: Genepop (Version 1.2): population genetics software for exact tests and ecumenicism. J Hered 1995, 86:248-249.

31. Labbe $P$, Lenormand T, Raymond M: On the worldwide spread of an insecticide resistance gene: a role for local selection. J Evol Biol 2005, 18:1471-1484

32. Raymond M, Berticat C, Weill M, Pasteur N, Chevillon C: Insecticide resistance in the mosquito culex pipiens: what have we learned about adaptation? Genetica 2001, 112-113:287-296.

33. Zhang L, Gao X, Liang P: Beta-cypermethrin resistance associated with high carboxylesterase activities in a strain of house fly, Musca domestica (Diptera: Muscidae). Pestic Biochem Physiol 2007, 89:65-72.

34. Alout $H$, Labbe P, Pasteur N, Weill M: High incidence of ace-1 duplicated haplotypes in resistant Culex pipiens mosquitoes from Algeria. Insect Biochem Mol Biol 2010, 41:29-35.

35. Labbe P, Berticat C, Berthomieu A, Unal S, Bernard C, Weill M, Lenormand T: Forty years of erratic insecticide resistance evolution in the mosquito Culex pipiens. PLoS Genet 2007, 3:e205.

36. Berticat C, Bonnet J, Duchon S, Agnew P, Weill M, Corbel V: Costs and benefits of multiple resistance to insecticides for Culex quinquefasciatus mosquitoes. BMC Evol Biol 2008, 8:104.
37. Rivero A, Magaud A, Nicot A, Vezilier J: Energetic cost of insecticide resistance in Culex pipiens mosquitoes. J Med Entomol 2011, 48:694-700

38. Bourguet D, Guillemaud T, Chevillon C, Raymond M: Fitness costs of insecticide resistance in natural breeding sites of the mosquito Culex pipiens. Evolution 2004, 58:128-135.

doi:10.1186/1756-3305-5-132

Cite this article as: Osta et al: Insecticide resistance to

organophosphates in Culex pipiens complex from Lebanon. Parasites \& Vectors 2012 5:132

\section{Submit your next manuscript to BioMed Central and take full advantage of:}

- Convenient online submission

- Thorough peer review

- No space constraints or color figure charges

- Immediate publication on acceptance

- Inclusion in PubMed, CAS, Scopus and Google Scholar

- Research which is freely available for redistribution 